\title{
Spatial and Temporal Characteristics of Cirrus Clouds over the Tibetan Plateau Based on CALIPSO and AIRS Observations
}

\author{
Hailei Liu $\left(\mathbb{D},{ }^{1}\right.$ Yuan Chen $\mathbb{D}^{1},{ }^{1}$ Shenglan Zhang $\mathbb{D},{ }^{1}$ Jilie Ding, ${ }^{1}$ Xiaobo Deng, \\ and Xingzhong Liu $^{2}$ \\ ${ }^{1}$ Key Laboratory of Atmospheric Sounding, Chengdu University of Information Technology, Chengdu 610225, China \\ ${ }^{2}$ Sichuan Meteorological Observation Data Center, Chengdu 610072, China \\ Correspondence should be addressed to Hailei Liu; liuhailei@cuit.edu.cn
}

Received 20 January 2019; Revised 1 April 2019; Accepted 7 May 2019; Published 11 June 2019

Academic Editor: Filomena Romano

Copyright (c) 2019 Hailei Liu et al. This is an open access article distributed under the Creative Commons Attribution License, which permits unrestricted use, distribution, and reproduction in any medium, provided the original work is properly cited.

\begin{abstract}
The spatial and temporal distribution characteristics of high clouds over the Tibetan Plateau (TP) were studied using the Atmospheric Infrared Sounder (AIRS) and the GCM-Oriented CALIPSO Cloud Product (CALIPSO-GOCCP) monthly mean cloud products from 2007 to 2017. The high clouds over the TP are dominated by cirrus and show seasonal variation characteristics. There were two distinct areas with the high occurrence of cirrus clouds in the area $\left(0^{\circ}-60^{\circ} \mathrm{N}, 75^{\circ}-103^{\circ} \mathrm{E}\right)$. One was located in the regions from the equator to $25^{\circ} \mathrm{N}$, and the other was within the latitude belt from $30^{\circ}$ to $40^{\circ} \mathrm{N}$. From January to May, cirrus clouds mainly occurred in the central and northern parts of the $\operatorname{TP}\left(30^{\circ}\right.$ to $\left.40^{\circ} \mathrm{N}\right)$, and the cirrus cloud fraction increased from January and reached its maximum ( 0.51) in April. From June to August, cirrus clouds mainly occurred in the southern part of the TP during summer. The cirrus clouds over the southern TP were relatively high (located in $10-17 \mathrm{~km}$ ) and manifested northward and southward movements. The ice clouds in the southern TP are associated with plateau deep convection activities and abundant vapor transmitted by the Asian monsoon. Cirrus clouds over the northern and central TP may be relevant to the atmospheric lift by an approaching cold front and topographic lifting. Moreover, the high clouds below $11 \mathrm{~km}$ are dominated by opaque clouds, while the nonopaque (or thin) and opaque (or thick) clouds above $11 \mathrm{~km}$ are comparable.
\end{abstract}

\section{Introduction}

Cirrus clouds are thin, wispy clouds that are generally located in the upper troposphere and lower stratosphere (cloud top pressure $<440 \mathrm{hPa}$ and ice phase) and have a major influence on the radiation budget of the Earth's climate system [1-3]. Cirrus clouds are globally distributed and undergo continuous changes in terms of area coverage, thickness, texture, and position [3]. The global cirrus cover has been estimated at approximately $20 \%$ to $35 \%$, and the cirrus cover is more than $70 \%$ over the tropics area [4]. The coverage, position, and thickness of these clouds, along with the sizes and shapes of ice crystal particles, are key factors involved in the radiative effects of clouds (cooling or warming) and associated climatic change (i.e., longterm radiative effects) $[2,5,6]$. Small variations in thin cirrus clouds (e.g., cirrus coverage, cirrus height, and sizes of ice crystal particles) can have effects on cloud radiative forcing, which are comparable in magnitude to the radiative forcing caused by human activities [7]. However, cirrus clouds are high and thin and usually occur as part of multilayered cloud systems, making it extremely difficult to obtain accurate satellite and ground-based observations of cirrus cloud characteristics [2]. Furthermore, these difficulties also influence modelling approaches, reducing the simulation accuracy of the radiative forcing of cirrus clouds.

The Tibetan Plateau (TP), with an average elevation of over $4000 \mathrm{~m}$ and an area of approximately $2.5 \times 10^{6} \mathrm{~km}^{2}$, is the highest and most extensive highland in the world. This prominent topographic feature has a major influence on regional and hemispheric atmospheric circulation patterns, particularly exerting substantial control on the Asian monsoons $[8,9]$. With the development of satellite detection technology, such as the Moderate Resolution Imaging Spectroradiometer (MODIS), Cloud Aerosol Lidar and 
Infrared Pathfinder Satellite Observations (CALIPSO), and Atmospheric Infrared Sounder (AIRS), satellite observations now provide opportunities for scientists to gain a comprehensive understanding of cirrus clouds on regional or global scales [10-13].

Gao et al. investigated the seasonal variations of cirrus clouds over the TP using the MODIS L3 monthly cirrus reflectance products [12]. Their results indicated that the high-cloud reflectance over the plateau reached its maximum and minimum in April and November, respectively. Using a four-year dataset of the MODIS cirrus cloud reflectance, Chen and Liu investigated the seasonal migration of cirrus clouds over the TP and the Asian monsoon region [14]. They showed that a large amount of cirrus clouds, which occur from March to April, were generated by relatively warm and moist air that was slowly lifted over a large area by an approaching cold front and topographic lifting. Jin used MODIS monthly products from 2000 to 2005 to analyze the geographical distribution as well as the seasonal and interannual variations of cirrus fraction over the TP [15]. The results indicated that the highest cirrus fraction occurred from March to May, whereas the lowest cirrus fraction occurred in the summer.

In general, MODIS mainly uses the $1.38 \mu \mathrm{m}$ (strong absorption channel of water vapor) reflectance to detect cirrus [16, 17]. However, MODIS has difficulty in distinguishing the weak signals of very thin cirrus clouds or thin cirrus under dry atmospheric condition (i.e., TP) [18, 19]. Detecting the properties of the thin cirrus clouds (optical depth less than 0.4 ) or those that are overlapped by lower clouds is a major challenge for passive remote-sensing instruments. Furthermore, MODIS mainly provides the daytime cirrus and cannot provide the cirrus vertical structure information. The A-Train is equipped with a variety of passive and active remote-sensing instruments, which provide unprecedented opportunities to study the cirrus cloud properties and the vertical structure of multilayer clouds [20]. Among these, the satellite-borne laser radar CALIPSO and the hyper-spectral sounder AIRS provide effective detection data to study cirrus clouds, particularly thin cirrus clouds [21].

In the past decades, previous researchers have studied the cloud characteristics and the relationship to the precipitation and cloud radiative effects over the TP using the CloudSat and CALIPSO observations [14, 22-25]. The review of these studies has been summarized by Yimin et al. [26]. Due to the topography-induced compression effects, the characteristics of cloud vertical structure and cloud radiative effects over the TP are significantly different with the neighbouring land regions and tropical ocean region in the south of the TP [23]. The clouds over the TP are mainly located in $4-12 \mathrm{~km}$, and the relative contribution of the single layer cloud on the total cloud fraction is larger than other Asian monsoon areas [23-25]. There are abundant high clouds over the TP; the cloud fraction and height show clear seasonal variation over the TP. There is less water vapor over the TP, and it limits the vertical height of the clouds and significantly affects the number of cloud layers and the cloud thickness [23].
These previous studies mainly focused on the cloud fraction and cloud vertical structure over the TP. However, the characteristics of high-level cloud fraction, vertical structure, and the phase (ice or liquid) have not been investigated in detail. In this study, we mainly focused on the analysis of the cirrus characteristics over the TP using the CALIPSO and AIRS observations.

\section{Datasets}

2.1. CALIPSO Data. The CALIPSO mission, launched on April 28, 2006, is a joint American-French collaboration that provided unique measurements to improve our understanding of the role of aerosols and clouds on the Earth's climate system. The combined observations from CALIPSO and the other satellites of the A-Train improve our ability to predict long-term climate change and seasonal to interannual climate variability [21]. The main instrument of CALIPSO is Cloud-Aerosol Lidar with Orthogonal Polarization (CALIOP), a two-wave length polarization-sensitive LIDAR that can measure the vertical profiles of aerosols and clouds at $30 \mathrm{~m}$ vertical and $333 \mathrm{~m}$ horizontal resolutions [27]. CALIOP can provide high-quality measurements of vertical backscattering coefficients and depolarization ratio profiles of aerosol and clouds. The measurements can be used to derive the vertical structure and properties of thin clouds and aerosols [28]. Moreover, CALIOP is sensitive to very thin cirrus clouds (e.g., subvisible cirrus clouds with optical depth about 0.01 ) and can provide information on multiple cloud layers [29].

In the current study, the GCM-Oriented CALIPSO Cloud Product (CALIPSO-GOCCP) monthly mean values of the three-dimensional distribution of the cloud fraction were used to analyze the vertical distribution characteristics of cirrus clouds over the TP. CALIPSO-GOCCP was first developed from the CALIPSO Level 1 attenuated backscatter measurements to evaluate the cloudiness simulated by general circulation models (GCMs) [30]. Based on the instantaneous LIDAR scattering ratio (SR) profiles and different SR thresholds, each atmospheric layer at a vertical resolution of $480 \mathrm{~m}$ is mainly labeled as clear $(0.01<\mathrm{SR}<1.2)$, cloudy $(\mathrm{SR}>5)$, fully attenuated $(\mathrm{SR}<0.01)$, or unclassified $(1.2<\mathrm{SR}<5)$ to avoid false cloud detection in the upper troposphere and lower stratosphere [30-32]. The cloudy profiles at each layer are then classified as liquid, ice, or undefined phase clouds using the polarization state of laser light scattered by the cloud particles (multiple scattering was considered) and temperature. The CALIPSO-GOCCP cloud phase detection algorithm and related evaluation were described in detail by Cesana and Chepfer [31]. Monthly cloud fractions are then computed by accumulating cloudy profiles during one month for each longitude-latitude grid box (e.g., $1 \times 1^{\circ}$ ).

The CALIPSO-GOCCP products include the monthly mean day, night, and averaged cloud fraction data. The CALIPSO-GOCCP products have been widely used for the study of cloud distribution and model evaluation [32,33]. In this study, the monthly average MapLowMidHighphase, 3D_CloudFraction_phase, and 3D_CloudFraction_OPAQ 
products (V 3.1.2) at $1^{\circ} \times 1^{\circ}$ grid for 11 years (2007-2017) were used. The MapLowMidHighphase products contain the liquid cloud cover, ice cloud cover, and undefined phase cloud cover at low level $(P>680 \mathrm{hPa}(\sim 3.36 \mathrm{~km}))$, midlevel $(440 \mathrm{hPa}<P<680 \mathrm{hPa})$, and high level $(P<440 \mathrm{hPa}$ $(\sim 6.72 \mathrm{~km}))$ following International Satellite Cloud Climatology Project (ISCCP) definition [30, 34]. The 3D_CloudFraction_phase products contain the liquid, ice, and uncertain cloud phase fraction profiles [31], while the 3D_CloudFraction_OPAQ products include the opaque and nonopaque (or thin) cloud fraction profiles [33].

In terms of cloud top pressure and optical thickness, high clouds are classified into cirrus clouds $(0<\tau<3.6)$, cirrostratus clouds $(3.6<\tau<23)$, and deep convective clouds $(23<\tau<379)$ on the basis of the ISCCP scheme [34]. The cloud fraction phase products can distinguish the pure ice clouds from the liquid phase clouds containing supercooled liquid. The 3D_CloudFraction_OPAQ products can be used to identify the not opaque (or thin) or opaque (or thick) ice clouds. In this study, the high-level ice clouds were considered as cirrus clouds.

2.2. AIRS Data. Since its launch into orbit on May 4, 2002, aboard the Aqua satellite of the National Aeronautics and Space Administration (NASA), AIRS has enhanced our understanding of Earth's weather and climate [10,35]. Aqua crosses the equator from south to north at 1:30 PM local time (daytime) in an ascending orbit and from north to south at 1:30 AM (nighttime) in a descending orbit. Aqua gives global, twice-daily coverage from an altitude of $705 \mathrm{~km}$. Over the past two decades, AIRS, a high spectral resolution sensor has provided extensive information in determining a variety of atmospheric parameters. AIRS can measure upwelling radiances in 2378 spectral channels, which range from $650 \mathrm{~cm}^{-1}$ to $2675 \mathrm{~cm}^{-1}$ [35]. Previous studies have demonstrated the ability of AIRS to measure the optical and microphysical properties of optically thin cirrus clouds [36]. Compared with other passive remote sensing instruments, AIRS provides more reliable information on cloud height, temperature, and effective cloud emissivity of cirrus clouds [18, 37]. Furthermore, AIRS can even detect the thin cirrus clouds with optical thickness of 0.1 at both day and nighttime [38].

In the present study, we used the AIRS level 3 (V6) standard monthly products from 2007 to 2017, at a spatial resolution of $1 \times 1^{\circ}$. The data products were obtained in hierarchical data format (HDF5) with associated latitudelongitude projection from the NASA-operated Giovanni portal (http://disc.sci.gsfc.nasa.gov/giovanni). The cloud fraction and cloud top pressure at standard pressure layers $(400,300,250,200,150$, and $100 \mathrm{hPa})$ were used in the current study.

\section{Results}

3.1. Spatial and Vertical Distribution from CALIPSO-GOCCP. Figure 1 shows the average CALIPSO-GOCCP monthly mean spatial distribution map of cirrus clouds over the TP and the nearby Asian monsoon region $\left(0\right.$ to $50^{\circ} \mathrm{N}, 70$ to $140^{\circ} \mathrm{E}$ ) from 2007 to 2017 . It shows significant seasonal variation and spatial distribution over the $\mathrm{TP}$ which is similar to the previous studies $[12,14,25]$. From January to May, cirrus clouds mainly occurred in the central and northern parts of the TP $\left(30^{\circ} \mathrm{N}-40^{\circ} \mathrm{N}\right)$, reaching their maximum in March. Few cirrus clouds can be seen during this period over the southern TP and subtropical regions, such as the Indian subcontinent and Indochina which is consistent with the previous studies $[14,25]$. In April, the cirrus fraction over the central and northern parts of the TP began to decrease, while cirrus clouds over eastern China and eastern Japan increased. Cirrus clouds were present in the tropical area throughout the year during the study period, and no major variation in cirrus clouds occurred over the area between the equator and $15^{\circ} \mathrm{N}$ between January and April.

In May, Cirrus clouds over the area between the equator and $20^{\circ} \mathrm{N}$ showed clear northward movements, which may be associated with the onset of the Asian monsoon [14]. From June, the cirrus cloud fraction over the Bay of Bengal increased dramatically associated with the Indian monsoon system, and the amount of cirrus clouds over the TP southern slope $\left(25^{\circ}\right.$ to $\left.30^{\circ} \mathrm{N}\right)$ gradually increased. This may be attributed to the deep convection and abundant water vapor associated with solar heating of the water surface of the Bay of Bengal [12]. The Bay of Bengal was characterized by a large amount of optically thin clouds from June to August. Furthermore, the value of the cirrus fraction over the region between $20^{\circ}$ and $30^{\circ} \mathrm{N}$ was low throughout the year, except during the summer monsoon season. This phenomenon may be related to the lack of water vapor transported to this area and the descending dry air caused by the sinking arm of the Hadley circulation. From July to August, a larger amount of high-level ice clouds are located around the southern edges of the TP. The high ice clouds increase slowly over the TP from September to December, while the ice clouds in the south of TP gradually reduce and retreat southward over the South China Sea and Bay of Bengal.

Figure 2 shows the latitude-time cross sections of GOCCP high-level ice and liquid cloud fractions averaged between $75^{\circ} \mathrm{E}-103^{\circ} \mathrm{E}$, which covers the entire TP $\left(27^{\circ} \mathrm{N}\right.$ to $40^{\circ} \mathrm{N}, 75^{\circ} \mathrm{E}$ to $103^{\circ} \mathrm{E}$, altitude $>3000 \mathrm{~m}$ ). There are two distinct bands of high-level ice cloud: one is located area between $32^{\circ} \mathrm{E}$ and $42^{\circ} \mathrm{E}$ and the other is between the equator and $30^{\circ} \mathrm{N}$. There are significant seasonal variations in the two bands. The high-level ice cloud fraction begins to increase gradually over the TP from January; it reaches maximum $(\sim 0.51)$ in March. From April, the high ice clouds over the TP starts to decrease and reaches the minimum in the central part of the TP. In addition, there is a clear northward propagation of high ice clouds starting from the TP, which is consistent with the previous study [14]. It is believed that the large amount of high ice clouds over the TP is generated locally [14]. For the other bands with a larger amount of ice cloud (equator and $30^{\circ} \mathrm{N}$ ), it comes from the tropics and is associated with northward movement of the Indian monsoon system. Furthermore, there is a distinct band of high- 

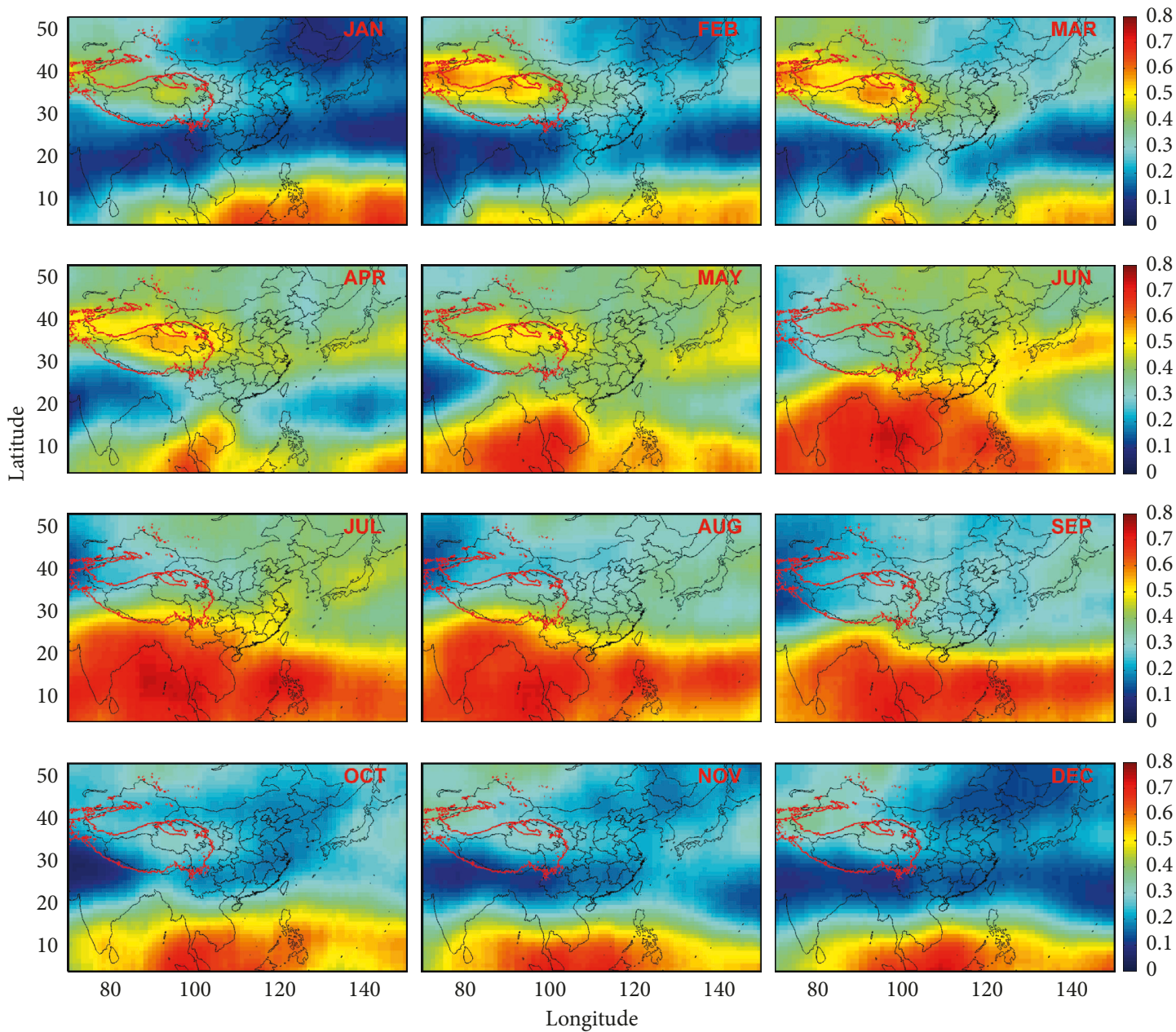

FIgURE 1: Monthly spatial distribution of the cirrus fraction over the TP and the nearby Asian regions from 2007 to 2017 . Red lines indicate the contour of height at $3000 \mathrm{~m}$.

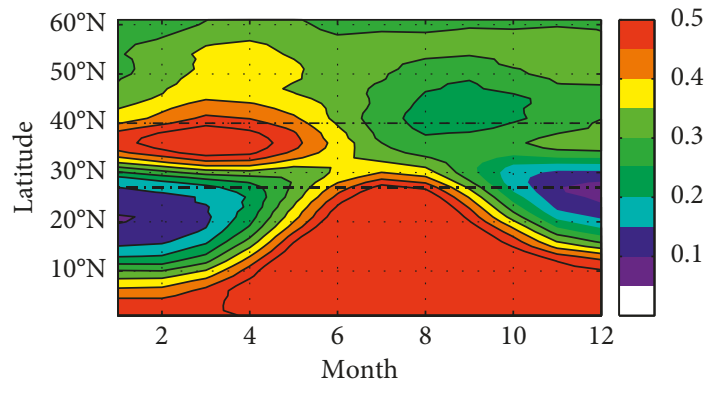

(a)

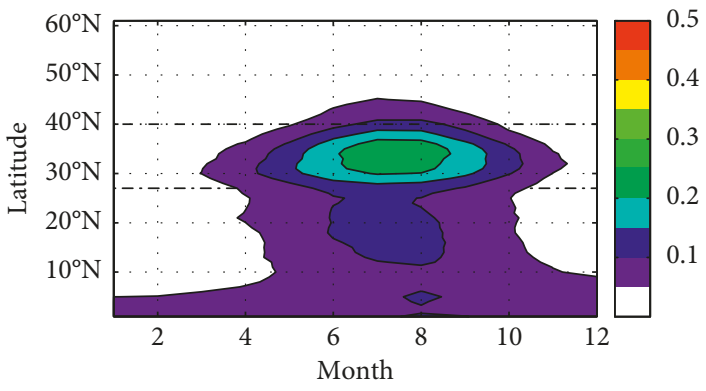

(b)

FIgure 2: Time-latitude cross sections of the GOCCP high-level ice (a) and liquid (b) cloud fractions averaged between $75^{\circ} \mathrm{E}-103^{\circ} \mathrm{E}$ during the period of 2007 to 2017 .

level liquid cloud between $27^{\circ} \mathrm{E}$ and $42^{\circ} \mathrm{E}$. The high liquid clouds exist only over the TP from April to October, with the maximum cloud fraction $(\sim 0.25)$ occurring in June to August.

As mentioned above, there are several sensors that can provide information about cloud heights. The main advantage of CALIPSO data is that they can provide very accurate information regarding the vertical distribution of clouds. Figures 3(a) and 3(b) show the time-altitude cross sections of the regional mean cirrus and high-level liquid clouds over the TP from January 2007 to December 2017, respectively. The high-level cloud shows seasonal variation over the TP. Moreover, the cirrus vertical distribution and the location of the maximum cirrus fraction vary year by 


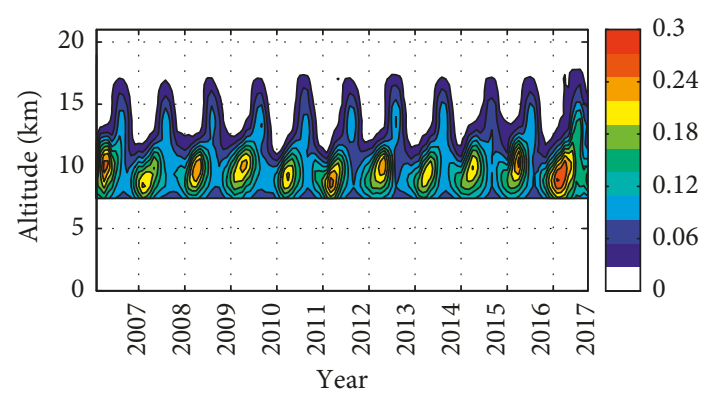

(a)

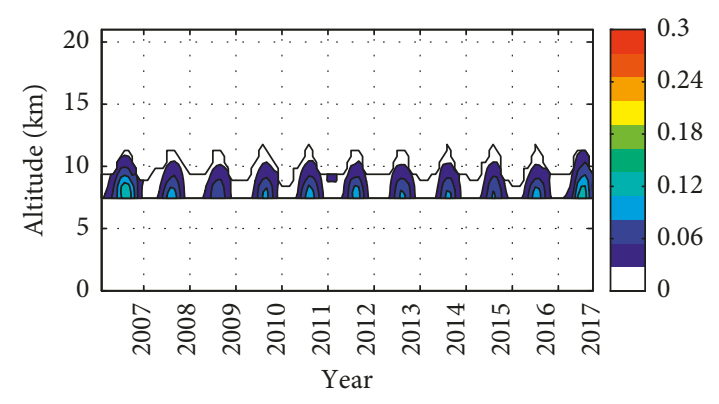

(b)

FIgURE 3: Time-altitude cross sections of the GOCCP monthly cirrus (a) and the high-level liquid clouds fraction (b) averaged over the TP from January 2007 to December.

year, for example, the maximum cirrus fraction occurs at $\sim 10 \mathrm{~km}$ in 2007 but at $8.5 \mathrm{~km}$ in 2012 . The atmosphere gets warmer from April and some ice clouds turn to liquid. There is a small amount of high-level liquid clouds $(<0.1)$ over the TP from April to October, which is mainly located below $10 \mathrm{~km}$ (Figure 3(b)).

The cirrus clouds over the TP are mainly distributed between 6 and $17 \mathrm{~km}$ (Figure 4). The cirrus clouds are mainly located in 6-12 km from January to May, with the maximum cirrus fraction occurring in $9-10 \mathrm{~km}$. From June to August, the cirrus clouds can reach up to $17 \mathrm{~km}$ and are commonly found over the southern TP (Figure 2(a)), which is mainly due to the deep convective activity over the region [23, 24]. In summer, abundant water vapor is converged to the plateau due to the outbreak of Asian summer monsoon. The influence of the topography, irradiation, and heat source enhances the convections over the TP [23, 24, 39]. Cirrus clouds between September and December were located at a lower altitude (approximately 6 to $10 \mathrm{~km}$ ).

As mentioned above, there are high-level liquid clouds over the TP which mainly occur from April to October. It can be seen that the high liquid clouds are mainly located between $7-10 \mathrm{~km}$. Yan et al. showed that the cloud amount over the TP has a single peak (located in 7-11 km) during January to April and two peaks (located in $5-8 \mathrm{~km}$ and $11-17 \mathrm{~km}$, respectively) in summer [23]. Figure 4 suggests that the peak at $5-8 \mathrm{~km}$ is contributed by both ice and liquid clouds, while the peak in $11-17 \mathrm{~km}$ is formed only by ice clouds. Moreover, the high clouds below $11 \mathrm{~km}$ are dominated by opaque clouds, while the nonopaque (or thin) and opaque (or thick) clouds above $11 \mathrm{~km}$ are comparable except in summer (Figure 5). The opaque clouds above $11 \mathrm{~km}$ in summer over the TP are clearly related to the appearance of deep convection activity over the region. The monthly mean thin ice cloud fraction is $\sim 0.08$ between $7-12 \mathrm{~km}$ during January to April, while the opaque ice cloud fraction is $\sim 0.14$.

To obtain more quantitative descriptions of the seasonal variations of cirrus clouds, we also calculated the monthly mean high-level ice and liquid cloud fractions averaged over the TP from 2007 to 2017. As shown in Figure 6, the high ice clouds (cirrus) were common and abundant over the TP particularly from January to May. The maximum cirrus cloud fraction occurred in March $(\sim 0.51)$, and then it gradually decreased and reached the minimum $(\sim 0.25)$ in October. For the high-level liquid cloud, the cloud fraction began to increase in January and reached the maximum $(\sim 0.2)$ in July or August and then started to decrease gradually to the minimum in December $(\sim 0.02)$.

Some results in this study are not consistent with previous investigations which were based on MODIS observations $[14,15]$. Although the maximum of the cirrus cloud fraction both occurred in March based on the CALIPSO or MODIS data, the MODIS analysis indicates that the minimum amount of cirrus clouds generally occurred in July or August over the TP and then gradually increased afterwards [14]. However, the lowest amount of cirrus clouds did not occur in July and August (but in October) according to the CALIPSO-GOCCP cloud products used in our study. The CALIPSO observations are also sensitive to very thin cirrus (such as subvisible cirrus with optical depth down to 0.01) [40].

\subsection{Vertical Distribution from AIRS Products. CALIPSO} observations can distinguish cirrus clouds effectively and provide accurate information regarding the spatial (both horizontal and vertical) distribution characteristics of cirrus clouds. However, CALIOP has a small footprint and a revisit time of 16 days; therefore, it is necessary to investigate the representativeness of the clouds properties from the satellite observations. In contrast, AIRS provides global coverage twice daily (day and night) with $13.5 \mathrm{~km}$ resolution. In this study, the AIRS cloud products were also used to analyze the vertical distribution characteristics of clouds cover over the TP. In this section, we present the spatial and temporal distribution characteristics of cirrus clouds over the TP based on the AIRS V6 L3 Standard monthly cloud products.

The CALIPSO analysis results support the conclusion that the spatial distribution of cirrus clouds over the TP significantly changes with time. Thus, in this section, we focused on the study of the time variation of cirrus clouds at six altitude levels $(100,150,200,250,300$, and $400 \mathrm{hPa})$ over $0-60^{\circ} \mathrm{N}$ latitude in the regions between $75^{\circ} \mathrm{E}$ and $103^{\circ} \mathrm{E}$. Figure 7 shows the time-latitude cross sections of the monthly cloud fraction averaged between 75 and $103^{\circ} \mathrm{E}$ at 


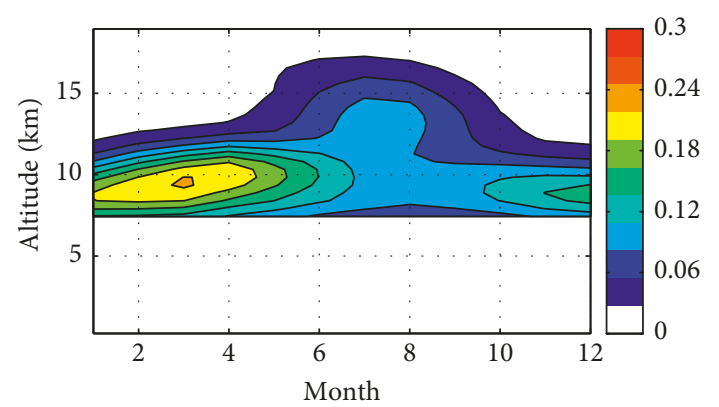

(a)

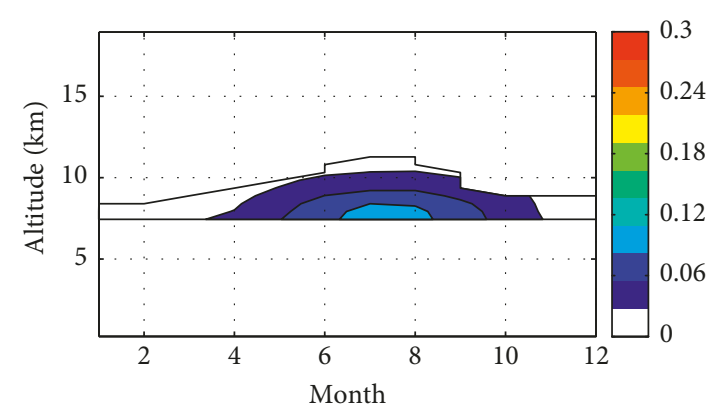

(b)

FIGURE 4: GOCCP monthly high-level ice cloud (cirrus) (a) and liquid cloud (b) fractions averaged over the TP during the period of 2007 to 2017.

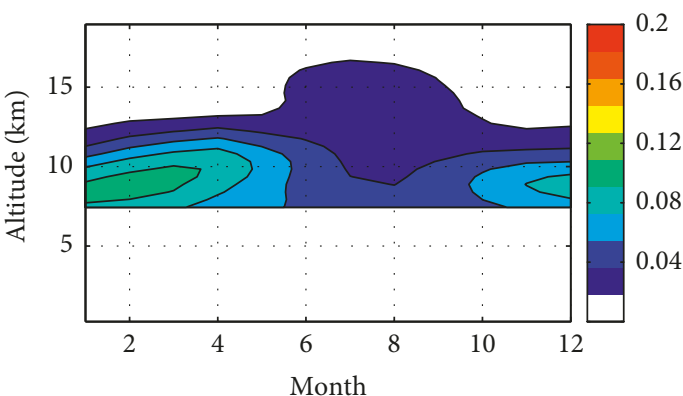

(a)

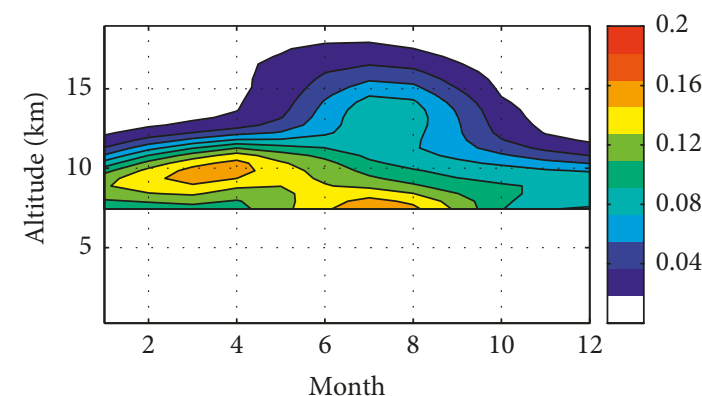

(b)

FIGURE 5: CALIPSO-GOCCP monthly high-level nonopaque (or thin) (a) and opaque (b) cloud fractions averaged over the TP during the period of 2007 to 2017.

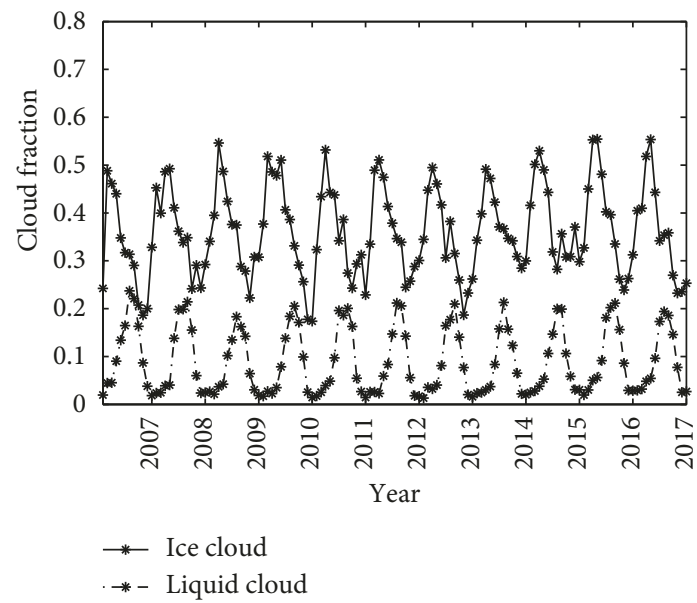

(a)

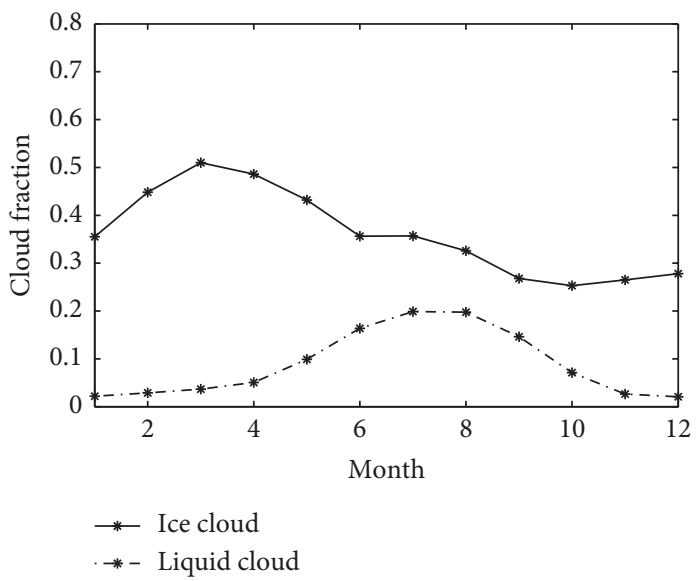

(b)

Figure 6: Time series of GOCCP monthly high-level ice and liquid clouds from 2007 to 2017 (a), and the seasonal variations of the high level ice and liquid clouds over the TP (b).

different altitudes from January 2007 to December 2017. It shows clear seasonal variations of cloud fraction over the TP at the altitudes from 400 to $100 \mathrm{hPa}$.

Similar to the CALIPSO-GOCCP results, two distinct bands with the high occurrence of cirrus clouds were observed between $0^{\circ}$ and $60^{\circ} \mathrm{N}$ : one was located in the regions from the equator to $30^{\circ} \mathrm{N}$ and the other was within the latitude belt from $30^{\circ}$ to $40^{\circ} \mathrm{N}$. Cirrus clouds in the region from the equator to $30^{\circ} \mathrm{N}$ had a relatively high altitude of above $200 \mathrm{hPa}$ $(\sim 11.5 \mathrm{~km})$. The clouds manifested clear seasonal variation with the northward and southward movements in association with the monsoon. Between June and August, these high clouds occurred in the southern slope of the TP, and the cirrus clouds at the $200 \mathrm{hPa}$ level could move northward to $35^{\circ} \mathrm{N}$. The cirrus was related to the onset of the Asian monsoon and can reach up to $150 \mathrm{hPa}(\sim 15.0 \mathrm{~km})$. 

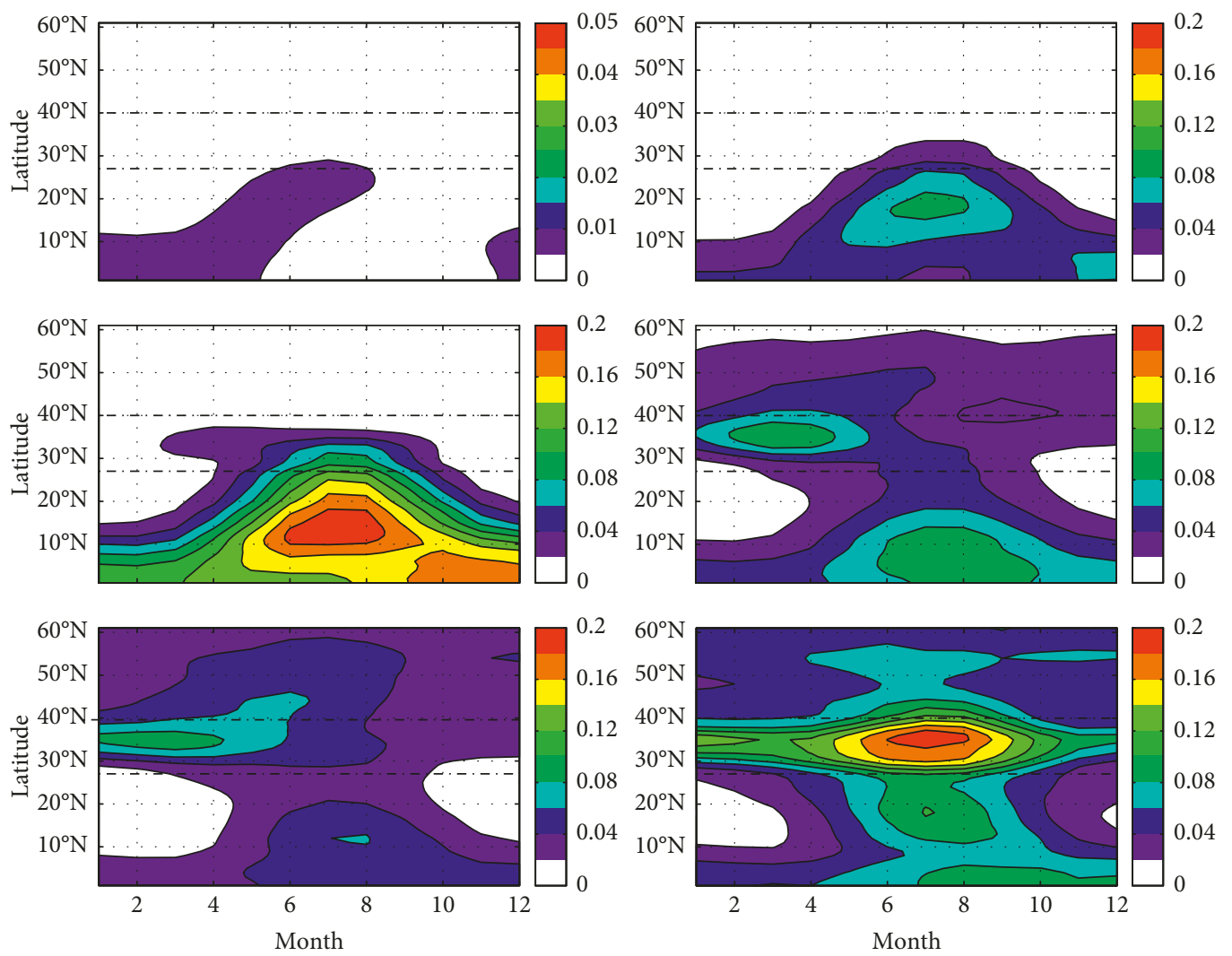

Figure 7: Time-latitude cross sections of the AIRS cloud fractions at different altitudes ((a) $100 \mathrm{hPa}$, (b) $150 \mathrm{hPa}$, (c) $200 \mathrm{hPa}$, (d) $250 \mathrm{hPa}$, (e) $300 \mathrm{hPa}$, and (f) $400 \mathrm{hPa}$ ) over averaged between $75^{\circ} \mathrm{E}-103^{\circ} \mathrm{E}$ during the period of 2007 to 2017 . The two horizontal dashed lines indicate $27^{\circ} \mathrm{N}$ and $40^{\circ} \mathrm{N}$, respectively.

In contrast, the cirrus fraction was small $(<0.1)$ between the equator and $30^{\circ} \mathrm{N}$ at the 250 to $400 \mathrm{hPa}$ levels, particularly during the spring and winter seasons. The region with a large amount of high clouds was located between $30^{\circ} \mathrm{N}$ and $50^{\circ} \mathrm{N}$ (the northern and central TP), and these clouds were mainly located at altitudes of 250 to $400 \mathrm{hPa}$. The largest amount of high clouds over this area was present in March. Abundant cirrus clouds occurred over the Taklimakan Desert in the north of the TP. This phenomenon is similar to the cirrus clouds found in the northern and central TP, and these clouds were more likely to have been lifted by the cold front than by the terrain [14].

In summary, high clouds show seasonal variation over the TP and seasonal difference in the southern, northern, and central TP. Cirrus clouds in the southern TP mostly occurred during the summer and at an altitude of above $250 \mathrm{hPa}$, whereas cirrus over the northern and central TP mainly occurred during January to May with the altitude of $250 \mathrm{hPa}$ to $400 \mathrm{hPa}$. Cirrus clouds over these two regions seem to be independent of each other. The one may be generated by relatively warm and moist air being slowly lifted by an approaching cold front and topographic lifting and the other related to the deep convection and monsoon systems [14, 15].

\section{Conclusions}

The spatial distribution characteristics and seasonal variation of high cloud over the TP were analyzed based on CALIPSO-GOCCP and AIRS monthly cloud products during the period from 2007 to 2017. In this study, we focus on the cirrus cloud fraction and the threedimensional structures over the TP, which will help us further understand the cloud distribution over this area. The distribution characteristics of high clouds over the TP from AIRS and CALIPSO-GOCCP data are consistent, which indicates that CALIPSO is representative of cloud detection over the TP. The high-level clouds over the TP are dominated by ice cloud all year round, while the high liquid cloud mainly occurred in $7-10 \mathrm{~km}$ during April to September.

There were two areas with the high occurrence of cirrus clouds between $0^{\circ}$ and $60^{\circ} \mathrm{N}, 75^{\circ}$ to $103^{\circ} \mathrm{E}$ : one was located in the regions from the equator to $25^{\circ} \mathrm{N}$ and the other was within the latitude belt from $30^{\circ}$ to $40^{\circ} \mathrm{N}$. The cirrus clouds in the southern, northern, and central TP seem to be independent of each other. In the northern and central TP, cirrus clouds mainly occur in January to May, with the maximum of cirrus fraction occurring in March. Cirrus clouds during this period are mainly located between $30^{\circ} \mathrm{N}$ and $40^{\circ} \mathrm{N}$ of the northern and central TP, with altitudes between 6 and $12 \mathrm{~km}$. Aside from the TP, abundant cirrus clouds occurred over the Taklimakan Desert.

From June to August, high cirrus clouds over the TP were mainly presented over the southern slope of the plateau, at altitudes of $10-17 \mathrm{~km}$. These clouds manifested northward and southward movements and can extend up to 
$35^{\circ} \mathrm{N}$ in the north in summer. The ice clouds in southern TP during summer are associated with plateau deep convection activities and abundant vapor transmitted by the Asia monsoon. Cirrus clouds over the northern and central TP may be relevant to the atmospheric lift by an approaching cold front and topographic lifting. Moreover, the high clouds below $11 \mathrm{~km}$ are dominated by opaque clouds, while the nonopaque and opaque clouds above $11 \mathrm{~km}$ are comparable except in summer. It is expected that the results are useful for improving our knowledge of cirrus cloud over the TP and cloud radiative effects estimation. In this study, the cirrus characteristics over the TP were analyzed using the monthly mean cloud data. The comprehensive cirrus information over the TP needs to be further investigated using the satellite and ground-based observations with higher temporal and spatial resolution.

\section{Data Availability}

The CALIPSO data used to support the findings of this study have been deposited in http://climserv.ipsl.polytechnique.fr/ cfmip-obs/Calipso_goccp.html. The AIRS data products were obtained in hierarchical data format (HDF5) with associated latitude-longitude projection from the NASAoperated Giovanni portal (http://disc.sci.gsfc.nasa.gov/ giovanni). All the data in this article are public and free.

\section{Conflicts of Interest}

The authors declare that there are no conflicts of interest regarding the publication of this paper.

\section{Acknowledgments}

This work was supported by the National Natural Science Foundation of China (41475026 and 41475032). The authors would like to thank the LMD/IPSL for providing CALIPSOGOCCP data and NASA for sharing the AIRS data.

\section{References}

[1] D. J. Cziczo, K. D. Froyd, C. Hoose et al., "Clarifying the dominant sources and mechanisms of cirrus cloud formation," Science, vol. 340, no. 6138, pp. 1320-1324, 2013.

[2] K.-N. Liou, "Influence of cirrus clouds on weather and climate processes: a global perspective," Monthly Weather Review, vol. 114, no. 6, pp. 1167-1199, 1986.

[3] D. P. Wylie and W. P. Menzel, "Eight years of high cloud statistics using HIRS," Journal of Climate, vol. 12, no. 1, pp. 170-184, 1999.

[4] A. E. Dessler and P. Yang, "The distribution of tropical thin cirrus clouds inferred from Terra MODIS data," Journal of Climate, vol. 16, no. 8, pp. 1241-1247, 2003.

[5] K. N. Liou, Y. Takano, Q. Yue, and P. Yang, "On the radiative forcing of contrail cirrus contaminated by black carbon," Geophysical Research Letters, vol. 40, no. 4, pp. 778-784, 2013.

[6] K. Sassen and J. R. Campbell, "A midlatitude cirrus cloud climatology from the facility for atmospheric remote sensing. Part I: macrophysical and synoptic properties," Journal of the Atmospheric Sciences, vol. 58, no. 5, pp. 481-496, 2001.
[7] D. M. Winker, J. Pelon, J. A. Coakley Jr. et al., "The CALIPSO mission," Bulletin of the American Meteorological Society, vol. 91, no. 9, pp. 1211-1230, 2010.

[8] B. Wang, Q. Bao, B. Hoskins, G. Wu, and Y. Liu, "Tibetan Plateau warming and precipitation changes in East Asia," Geophysical Research Letters, vol. 35, no. 14, article L14702, 2008.

[9] G. Wu, Y. Liu, Q. Zhang et al., "The influence of mechanical and thermal forcing by the Tibetan Plateau on Asian climate," Journal of Hydrometeorology, vol. 8, no. 4, pp. 770-789, 2007.

[10] M. T. Chahine, T. S. Pagano, H. H. Aumann et al., "Airs," Bulletin of the American Meteorological Society, vol. 87, no. 7, pp. 911-926, 2006.

[11] R. A. Frey, S. A. Ackerman, Y. Liu et al., "Cloud detection with MODIS. Part I: improvements in the MODIS cloud mask for collection 5," Journal of Atmospheric and Oceanic Technology, vol. 25, no. 7, pp. 1057-1072, 2008.

[12] B.-C. Gao, P. Yang, G. Guo, S. K. Park, W. J. Wiscombe, and B. Chen, "Measurements of water vapor and high clouds over the Tibetan Plateau with the terra MODIS instrument," IEEE Transactions on Geoscience and Remote Sensing, vol. 41, no. 4, pp. 895-900, 2003.

[13] H. Shang, H. Letu, T. Y. Nakajima et al., "Diurnal cycle and seasonal variation of cloud cover over the Tibetan Plateau as determined from Himawari-8 new-generation geostationary satellite data," Scientific Reports, vol. 8, no. 1, p. 1105, 2018.

[14] B. Chen and X. Liu, "Seasonal migration of cirrus clouds over the Asian monsoon regions and the Tibetan Plateau measured from MODIS/Terra," Geophysical Research Letters, vol. 32, no. 1, article L01804, 2005.

[15] M. Jin, "MODIS observed seasonal and interannual variations of atmospheric conditions associated with hydrological cycle over Tibetan Plateau," Geophysical Research Letters, vol. 33, no. 19, article L19707, 2006.

[16] B.-C. Gao and Y. J. Kaufman, "Selection of the $1.375-\mu \mathrm{m}$ MODIS channel for remote sensing of cirrus clouds and stratospheric aerosols from Space," Journal of the Atmospheric Sciences, vol. 52, no. 23, pp. 4231-4237, 1995.

[17] K. Meyer and S. Platnick, "Utilizing the MODIS $1.38 \mu \mathrm{m}$ channel for cirrus cloud optical thickness retrievals: algorithm and retrieval uncertainties," Journal of Geophysical Research: Atmospheres, vol. 115, no. 24, article D24209, 2010.

[18] C. J. Stubenrauch, S. Cros, A. Guignard, and N. Lamquin, “A 6-year global cloud climatology from the atmospheric infrared sounder AIRS and a statistical analysis in synergy with CALIPSO and CloudSat," Atmospheric Chemistry and Physics, vol. 10, no. 15, pp. 7197-7214, 2010.

[19] E. Ben-Dor, "A precaution regarding cirrus cloud detection from airborne imaging spectrometer data using the $1.38 \mu \mathrm{m}$ water vapor band," Remote Sensing of Environment, vol. 50, no. 3, pp. 346-350, 1994.

[20] G. L. Stephens, D. G. Vane, R. J. Boain et al., "The CloudSat mission and the a-train," Bulletin of the American Meteorological Society, vol. 83, no. 12, pp. 1771-1790, 2002.

[21] D. M. Winker, M. A. Vaughan, A. Omar et al., "Overview of the CALIPSO mission and CALIOP data processing algorithms," Journal of Atmospheric and Oceanic Technology, vol. 26, no. 11, pp. 2310-2323, 2009.

[22] Y. Zhang, H. Chen, and R. Yu, "Vertical structures and physical properties of the cold-season stratus clouds downstream of the Tibetan Plateau: differences between daytime and nighttime," Journal of Climate, vol. 27, no. 18, pp. 6857-6876, 2014.

[23] Y. Yan, Y. Liu, and J. Lu, "Cloud vertical structure, precipitation, and cloud radiative effects over Tibetan Plateau and 
its neighboring regions," Journal of Geophysical Research: Atmospheres, vol. 121, no. 10, pp. 5864-5877, 2016.

[24] Y. Luo, R. Zhang, and W. Qian, "Intercomparison of deep convection over the Tibetan Plateau-Asian monsoon region and subtropical North America in boreal summer using CloudSat/CALIPSO data," Journal of Climate, vol. 24, no. 8, pp. 2164-2177, 2011.

[25] H. Cai, X. Feng, Q. Chen, Y. Sun, Z. Wu, and X. Tie, "Spatial and temporal features of the frequency of cloud occurrence over China based on CALIOP," Advances in Meteorology, vol. 2017, Article ID 4548357, 11 pages, 2017.

[26] L. Yimin, Y. Yafei, L. Jianhua, and L. Xiaolin, "Review of current investigations of cloud, radiation and rainfall over the Tibetan Plateau with the CloudSat/CALIPSO dataset," Chinese Journal of Atmospheric Sciences, vol. 42, no. 4, pp. 847858, 2018.

[27] D. M. Winker, W. H. Hunt, and M. J. McGill, "Initial performance assessment of CALIOP," Geophysical Research Letters, vol. 34, no. 19, article L19803, 2007.

[28] K.-G. Karlsson and A. Dybbroe, "Evaluation of arctic cloud products from the EUMETSAT climate monitoring satellite application facility based on CALIPSO-CALIOP observations," Atmospheric Chemistry and Physics, vol. 10, no. 4, pp. 1789-1807, 2010.

[29] K. Sassen, Z. Wang, and D. Liu, "Global distribution of cirrus clouds from CloudSat/cloud-aerosol lidar and infrared pathfinder satellite observations (CALIPSO) measurements," Journal of Geophysical Research, vol. 113, no. 8, article D00A12, 2008.

[30] H. Chepfer, S. Bony, D. Winker et al., "The GCM-oriented CALIPSO cloud product (CALIPSO-GOCCP)," Journal of Geophysical Research, vol. 115, no. 4, article D00H16, 2010.

[31] G. Cesana and H. Chepfer, "Evaluation of the cloud thermodynamic phase in a climate model using CALIPSOGOCCP," Journal of Geophysical Research: Atmospheres, vol. 118, no. 14, pp. 7922-7937, 2013.

[32] H. Chepfer, G. Cesana, D. Winker, B. Getzewich, M. Vaughan, and Z. Liu, "Comparison of two different cloud climatologies derived from CALIOP-attenuated backscattered measurements (level 1): the CALIPSO-ST and the CALIPSOGOCCP," Journal of Atmospheric and Oceanic Technology, vol. 30, no. 4, pp. 725-744, 2013.

[33] R. Guzman, H. Chepfer, V. Noel et al., "Direct atmosphere opacity observations from CALIPSO provide new constraints on cloud-radiation interactions," Journal of Geophysical Research: Atmospheres, vol. 122, no. 2, pp. 1066-1085, 2017.

[34] W. B. Rossow and R. A. Schiffer, "Advances in understanding clouds from ISCCP," Bulletin of the American Meteorological Society, vol. 80, no. 11, pp. 2261-2287, 1999.

[35] H. H. Aumann, M. T. Chahine, C. Gautier et al., "AIRS/ AMSU/HSB on the aqua mission: design, science objectives, data products, and processing systems," IEEE Transactions on Geoscience and Remote Sensing, vol. 41, no. 2, pp. 253-264, 2003.

[36] Q. Yue, K. N. Liou, S. C. Ou, B. H. Kahn, P. Yang, and G. G. Mace, "Interpretation of AIRS data in thin cirrus atmospheres based on a fast radiative transfer model," Journal of the Atmospheric Sciences, vol. 64, no. 11, pp. 3827-3842, 2007.

[37] B. H. Kahn, M. T. Chahine, G. L. Stephens et al., "Cloud type comparisons of AIRS, CloudSat, and CALIPSO cloud height and amount," Atmospheric Chemistry and Physics, vol. 8, no. 5, pp. 1231-1248, 2008.

[38] B. H. Kahn, C. K. Liang, A. Eldering, A. Gettelman, Q. Yue, and K. N. Liou, "Tropical thin cirrus and relative humidity observed by the atmospheric infrared sounder," Atmospheric Chemistry and Physics, vol. 8, no. 6, pp. 1501-1518, 2008.

[39] Q. S. He, C. C. Li, J. Z. Ma et al., "The properties and formation of cirrus clouds over the Tibetan Plateau based on summertime lidar measurements," Journal of the Atmospheric Sciences, vol. 70, no. 3, pp. 901-915, 2013.

[40] J. Huang, N. C. Hsu, S.-C. Tsay et al., "Susceptibility of aerosol optical thickness retrievals to thin cirrus contamination during the BASE-ASIA campaign," Journal of Geophysical Research: Atmospheres, vol. 116, no. 8, 2011. 

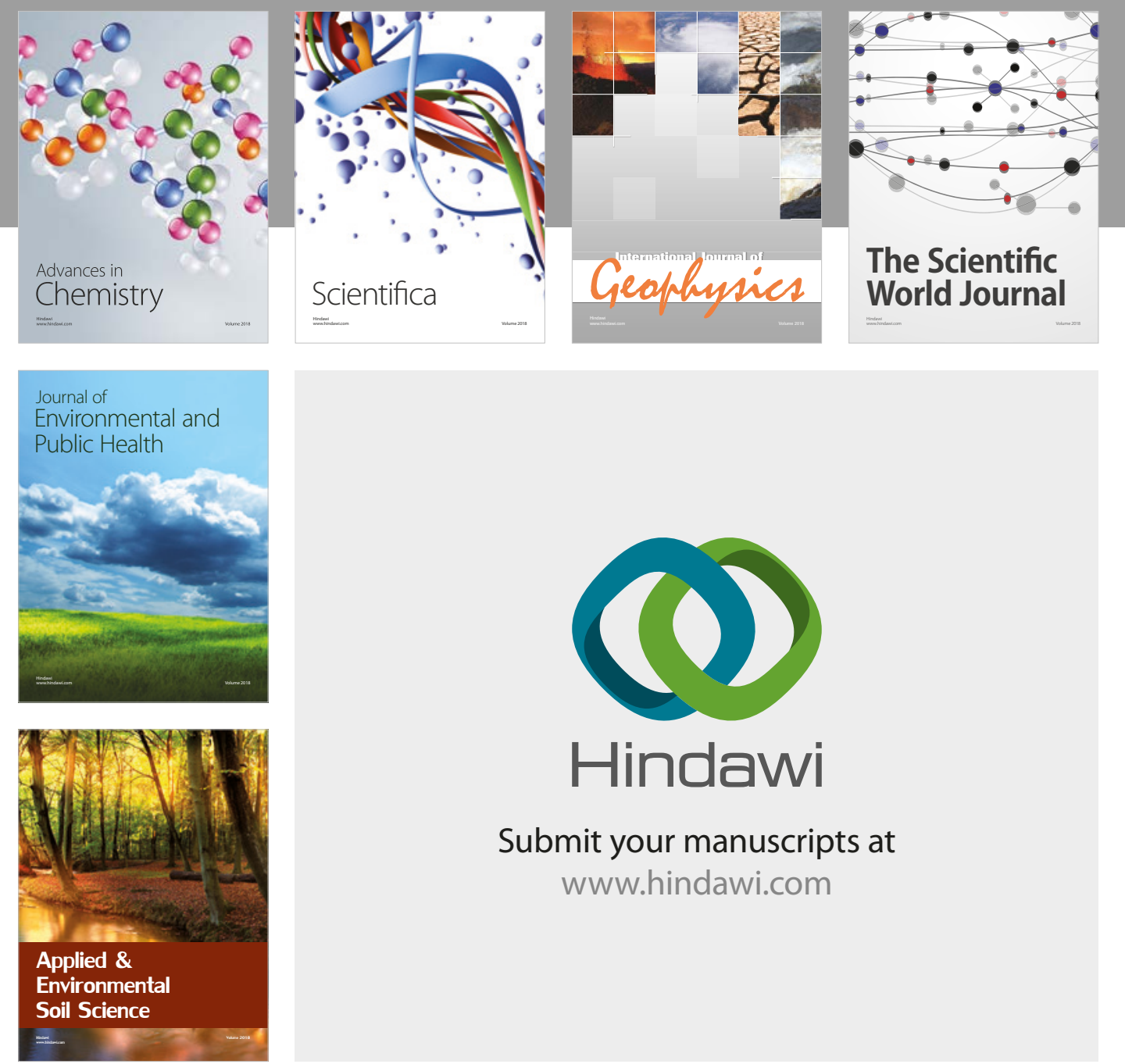

The Scientific

\section{World Journal}
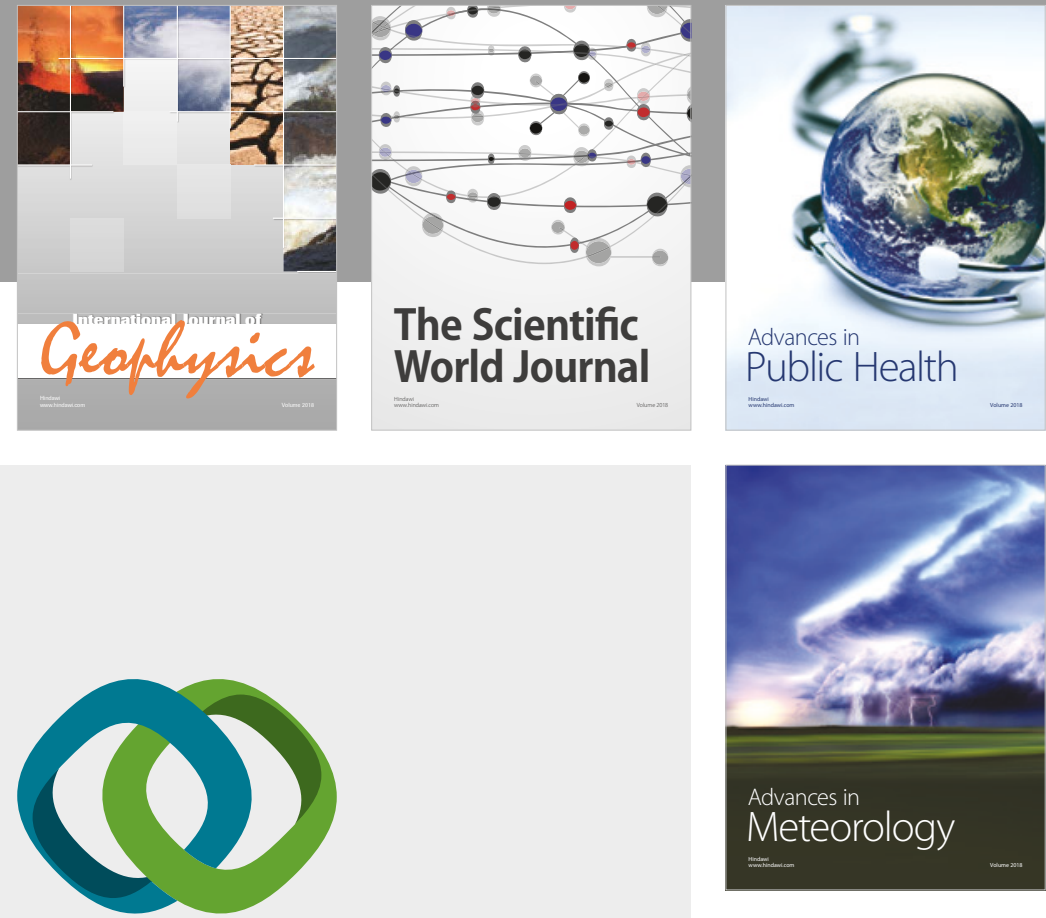

Advan

Public Health

\section{Hindawi}

Submit your manuscripts at

www.hindawi.com
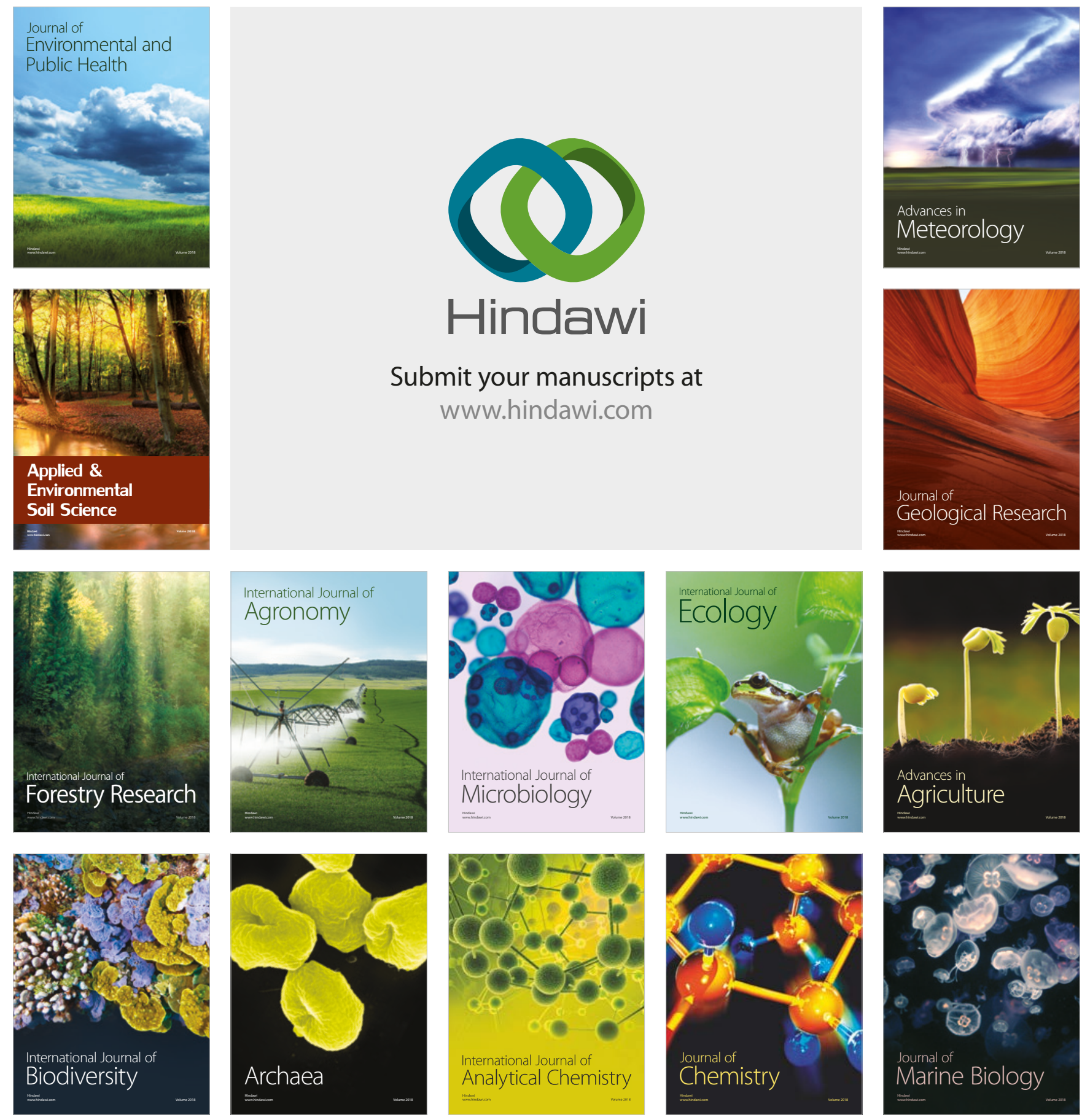